\title{
THE IMPACT OF THE SUPPORT SYSTEM'S KINEMATIC STRUCTURE ON SELECTED KINEMATIC AND DYNAMIC QUANTITIES OF AN EXPERIMENTAL CRANE
}

\author{
Arkadiusz TRABKA* \\ ${ }^{*}$ Faculty of Mechanical Engineering and Computer Science, Department of Engineering Fundamentals, \\ University of Bielsko-Biala, ul. Willowa 2, 43-309 Bielsko-Biała, Poland \\ atrabka@ath.bielsko.pl
}

\begin{abstract}
This paper presents a comparative analysis of two kinematic structures of the support system (with supports with bilateral and unilateral constraints), which were used in an experimental model of a crane. The computational model was developed by using the ADAMS software. The impact of the kinematic structure of the support system on selected kinematic and dynamic values that were recorded during the slewing motion was analysed. It was found, among other things, that an increased number of degrees of freedom of the support system leads to multiple distortions of time characteristics of kinematic and dynamic quantities.
\end{abstract}

Key words: Experimental Crane, Multi-Body Systems, Supports, Unilateral Constraints, Bilateral Constraints

\section{INTRODUCTION}

Cranes are complex mechatronic systems whose operation reveals different types of constructional and technological problems as well as problems related to controlling cranes' operation (Trabka, 2014). Many scientific papers were written in order to find the answers to the above-mentioned problems. Their authors most often used numerical models to analyse real structures. The models and the results of analyses were verified either by using computational models that had been developed based on other methods (Cha et al., 2010; Geisler and Sochacki, 2011; Paszkiewicz et al., 1999) or by using experimental models that had been constructed especially for this purpose (Jerman et al., 2004; Kłosiński, 2005; Maczyński, 2000; Smoczek, 2014; Smoczek and Szpytko, 2012; 2014; Sochacki, 2007; Terashima et al., 2007; Uchiyama, 2009; Uchiyama et al., 2013; Wu, 2006). Verification tests were conducted on real objects less frequently due to their high costs (Araya et al., 2004; Blackburn et al., 2010; Kilicaslan et al., 1999; Mijailović, 2011; Sosna, 1984; Trąbka, 2014).

Experimental models should have the same properties as the structures based on which these models have been developed (or properties that are as similar as possible to the properties of such structures). The models should be similar to real structures in terms of geometry, kinematics and dynamics in order to meet these conditions (Trombski, 2003). Since it is very difficult to meet all of the above criteria at the same time, certain construction solutions that are used in experimental models (for example, a crane's supports fastened to the ground) may raise concerns as to whether the properties of real objects are mapped correctly.

This paper presents a computational model of a mobile crane with a telescopic boom which was developed based on an experimental crane in which two variants of the kinematic structure of the support system were used. What was analysed was how the selection of a kinematic structure of the support system (with supports with unilateral or bilateral constraints) influences selected kinematic and dynamic quantities of the crane.

\section{COMPUTATIONAL MODEL OF AN EXPERIMENTAL CRANE}

The computational model was developed by using multi-body system analysis software ADAMS based on the real structure of an experimental crane (Fig. 1).

a)

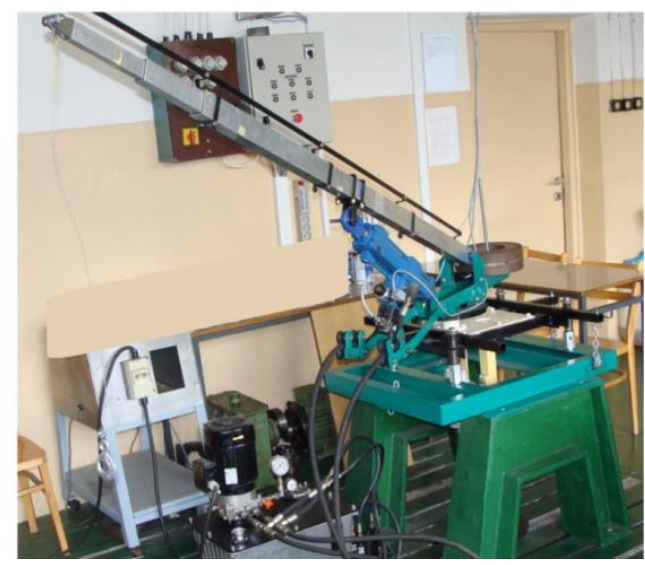

b)

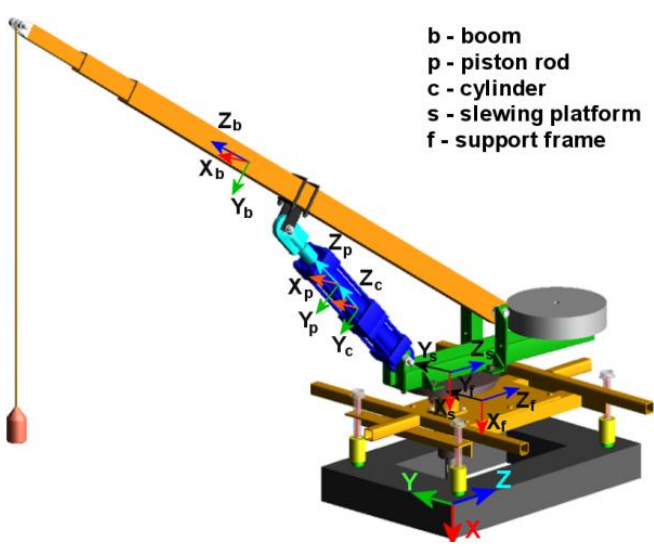

Fig. 1. a) Experimental crane, b) Computational model 
The model included the majority of a crane's structural components, which were assumed to be non-deformable except for the supports and the rope. Two variants of the computational model were developed. In variant V1 the kinematic structure of a support system with supports having bilateral constraints was used (Fig. 2a) whereas in variant V2 supports with unilateral constraints were used (Fig. 2b).

a)

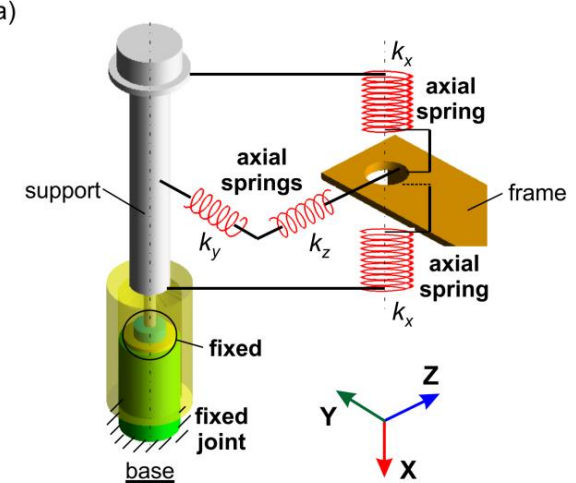

b)

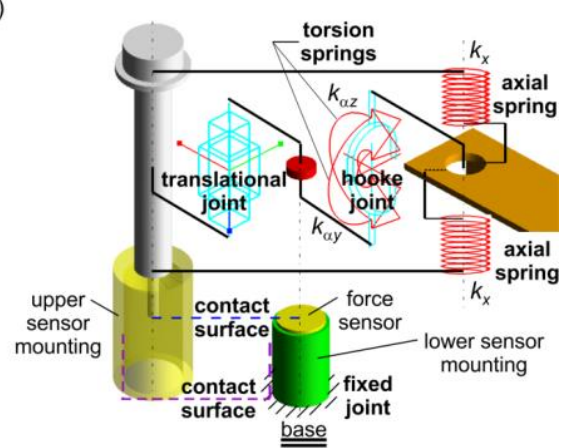

Fig. 2. Supports with: a) bilateral constraints (V1),

b) unilateral constraints (V2)

The dimensions, masses and mass moments of inertia of the model's parts were determined based on the measurements of a real structure and the geometrical models of these parts which had been developed by using the Inventor software (Tab. 1).

The stiffnesses and dampings of the axial springs that were used to model the supports were determined experimentally. Since the same set of eight compression springs was used in both variants of the experimental crane to construct the supports, and all these springs came from the same production batch, it was decided that the same stiffness $k_{x}$ should be adopted for all of the axial springs in the computational model. This stiffness was determined for a spring which had been randomly selected from the set of springs based on a series of 10 measurements of the dependence of deformation on the load, which were made by using a universal testing machine FP10. For each dependence of deformation on the load an average stiffness $k_{N}$ was calculated based on equation (1) and then a substitute stiffness $k_{x}=$ $17.25 \times 10^{3} \mathrm{~N} / \mathrm{m}$ was determined by using equation (2).

$k_{N}=\frac{1}{m} \cdot \sum_{i=1}^{i=m} \frac{\Delta P_{i}}{\Delta l_{i}}$

$k_{x}=\frac{1}{s} \cdot \frac{1}{n} \cdot \sum_{N=1}^{N=n} k_{N}$

where: $N$ - measurement no., $m$ - number of changes in a spring load, $s=2-$ number of springs that are connected in parallel to each other in the crane support's model, $n$ - number of meas- urements, $\Delta P_{i}-i$-th change in the load carried by a spring, $\Delta l_{i}-$ $i$-th change in a spring's length.

Damping coefficients $c_{u}$ in the supports (systems of springs) were determined for the directions of the $X, Y$ and $Z$ axes of a reference frame by using the free vibration method. The damping coefficients were calculated by using equation (3) based on the changes in the position of the support frame over time with respect to the base (Giergiel, 1986).

$c_{u}=\frac{2 \cdot M \cdot \delta}{T}$

where: $M$ - mass of the system of supports which depends on the location of the sensor of displacements and the direction of movement, $\delta$ - logarithmic damping decrement, $T$ - period of damped vibration.

For every direction of movement 10 measurements were carried out and the average damping coefficients $c_{s}$ were calculated based on these measurements. In the computational model a damping coefficient was assigned to each of the springs; such a damping coefficient was reduced in relation to the calculated average value proportionately to the number of the supports that were located in the area of the frame's recorded movement as well as to the number of springs that were connected in parallel to each other in a support. Finally, the following values were adopted for calculations: $c_{s x}=0.277 \times 10^{3} \mathrm{~N} \cdot \mathrm{s} / \mathrm{m}, \quad c_{s y}=$ $0.47 \times 10^{3} \mathrm{~N} \cdot \mathrm{s} / \mathrm{m}, c_{s z}=0.59 \times 10^{3} \mathrm{~N} \cdot \mathrm{s} / \mathrm{m}$.

Apart from axial stiffnesses of the springs which were determined experimentally, also the stiffnesses of systems of springs, perpendicular to their axes, were taken into account. Lateral stiffnesses of the systems of springs $\left(k_{y}=k_{z}=114 \times\right.$ $10^{3} \mathrm{~N} / \mathrm{m}$ ) were determined numerically; both the computational model and the calculations themselves were carried out by using the Ansys v11 software and following a method described in Kłosiński and Trabka (2010).

Tab. 1. Masses and mass moments of inertia of the model's parts

\begin{tabular}{|l|c|c|c|c|}
\hline \multirow{2}{*}{$\begin{array}{c}\text { Name of a } \\
\text { given part }\end{array}$} & $\begin{array}{c}\text { Mass } \\
{[\mathrm{kg}]}\end{array}$ & \multicolumn{3}{|c|}{$\begin{array}{c}\text { Mass moments of inertia with respect } \\
\text { to the centres of masses of the } \\
\text { model's parts } \\
{\left[\mathbf{k g} \cdot \mathbf{m}^{2}\right]}\end{array}$} \\
\cline { 3 - 5 } & & $J_{s x}$ & $J_{s y}$ & $J_{s z}$ \\
\hline Support frame & 17.3 & 0.792 & 0.567 & 0.235 \\
\hline Slewing platform & 20.2 & 0.688 & 0.706 & 0.128 \\
\hline Boom & 4.5 & 0.937 & 0.936 & 0.0025 \\
\hline Piston rod & 3.7 & 0.068 & 0.067 & 0.0008 \\
\hline Cylinder & 11 & 0.21 & 0.21 & 0.01 \\
\hline
\end{tabular}

Torsion springs were added to the computational model for supports with unilateral constraints. Each of the support screws was connected to the support frame with two torsion springs. They were placed on planes that were parallel to planes $X Y$ and $X Z$ of the frame of reference. The stiffnesses of torsion springs were determined experimentally based on tests of the dependence of the support's angle of rotation on the support frame as a function of the torsional moment. The same value of stiffness for all of the supports was adopted ( $k_{a y}=k_{a z}=$ $78.2 \mathrm{~N} \cdot \mathrm{m} / \mathrm{deg})$.

At the points of contact between support screws and force sensors, contact joints were applied. As for these joints, the possibility of friction was taken into account (the Coulomb friction model was used). 


\section{NUMERICAL ANALYSIS OF THE MODEL}

\subsection{Assumptions for the calculations}

- The model's initial position corresponds to a crane being in a state of static equilibrium; the initial tension of springs was taken into account;

- Flexibilities, clearances and friction in joints between the model parts were not taken into account;

- Flexibilities, clearances and friction in the drive were not taken into account; a constant value of the reduction gear ratio $i=20$ was adopted;

- The rope's flexibility and the flexibility of the luffing hydraulic cylinder were not included in the model;

- A constant step of integration was $0.001 \mathrm{~s}$.

\subsection{Calculations} model.

Calculations were carried out for two configurations of the

Configuration 1 included a boom inclined to the level at an angle of $22^{\circ}$, a crane radius of $1.64 \mathrm{~m}$, a load of $3 \mathrm{~kg}$ and a counterweight of $45 \mathrm{~kg}$.

Configuration 2 included a boom inclined to the level at an angle of $35^{\circ}$, a crane radius of $1.43 \mathrm{~m}$, a load of $1 \mathrm{~kg}$ and a counterweight of $17 \mathrm{~kg}$.

In both cases the distance between the centre of mass of the load and the point where the rope was attached to the boom was $1 \mathrm{~m}$. The rotation angle of the body relative to the chassis was $90^{\circ}$. The kinematic input function was used for the slewing motion. The forms of the functions that were used to describe the input functions are presented in Fig. 3.

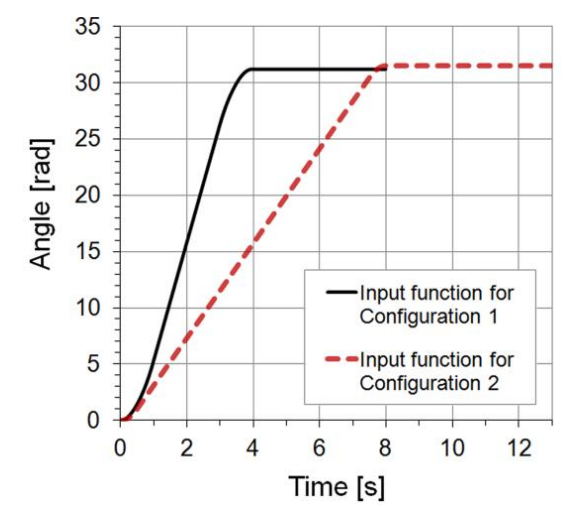

Fig. 3. Slewing motion input functions for both model configurations

The calculations were started by checking the correctness of the computational model. In order to do this, first it was checked whether there were no redundant constraints in the model; afterwards, the model was verified. Verification was conducted for both configurations by comparing the calculated support loads with the loads that were recorded during the tests. The results of the comparison for configuration 2, variant V2, are shown in Fig. 4. It was found that the model properly mapped the real object and the visible differences between characteristics were due to the omission of the flexibilities of particular parts as well as the flexibilities of connections, the friction and clearances in the connections, and most of all due to the omission of clearances in the drive.

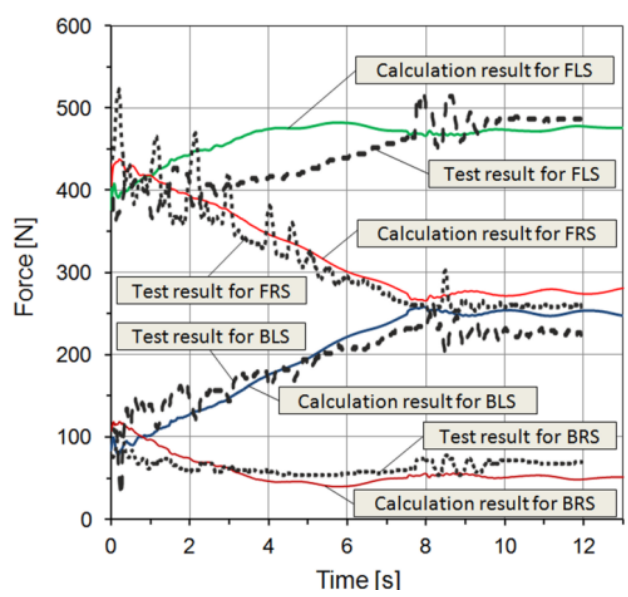

Fig. 4. A comparison of support loads for configuration 2, variant V2 with the loads that were recorded during the tests (BLS - back left support, BRS - back right support, FLS - front left support, FRS - front right support)

\subsection{Results and discussion}

This paper presents an evaluation of the impact of the kinematic structure of the support system on the trajectory of the load, the speed of rotation of the body relative to the chassis and the support loads.

Calculation results for configuration 1 of the computational model are presented in Fig. 5. A dashed line was used for variant $\mathrm{V} 1$ of the model and a solid line was used for variant V2. Fig. 5a presents the trajectory of the centre of mass of the load and Fig. $5 \mathrm{~b}$ shows the changes in the speed of rotation of the body relative to the chassis. The distribution of the support loads is shown in Fig. $5 c$ whereas Fig. $5 d$ presents a quantitative comparison of the changes in variant V2 support loads in relation to variant V1.

The calculation results for configuration 2 of the computational model are presented in the next four figures (Figs. 6a-d) in the same way as for configuration 1.

Based on the calculation results (Figs. 5-6) it was found that:

- A change in the kinematic structure of the support system does not lead to significant differences in the load's trajectory regardless of the configuration and input functions.

- The speed of rotation of the body relative to the chassis is non-linear for both variants of the model in configuration 1 and for variant V2 in configuration 2. Moreover, this speed undergoes constant changes and these changes are considerably greater for variant $\mathrm{V} 2$ than for variant $\mathrm{V} 1$.

- The changes in the speed of rotation of the body are closely related to the vibration of the support frame which is caused by the horizontal displacement of the supports. Due to the additional degrees of freedom these vibrations have larger amplitudes and cause greater speed changes for variant V2.

- An increased number of the degrees of freedom of the support system, in particular the introduction of the possibility of the supports sliding against the base, contributes to the occurrence of short-term (impulsive) variations in the support loads.

- The maximum increase of the support loads, which is related to the change in their kinematic structure, does not exceed $14.7 \%$ for configuration 1 (Fig. 5d) and 13\% for configuration 2 (Fig. 6d). 
a)

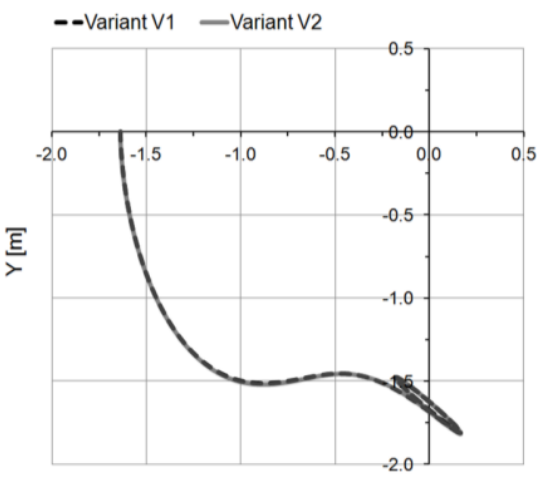

$Z[\mathrm{~m}]$

c)

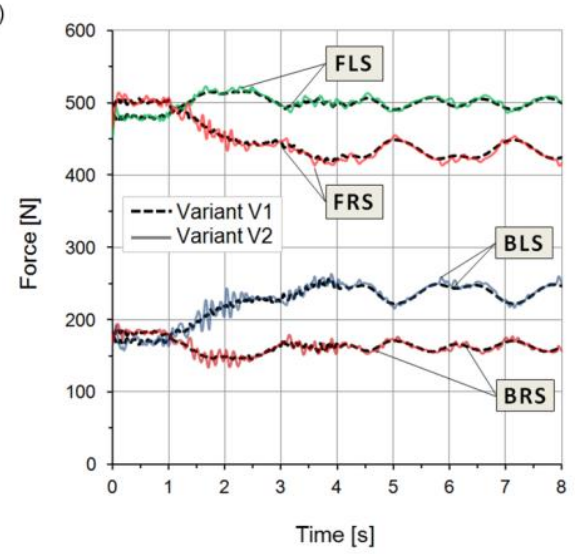

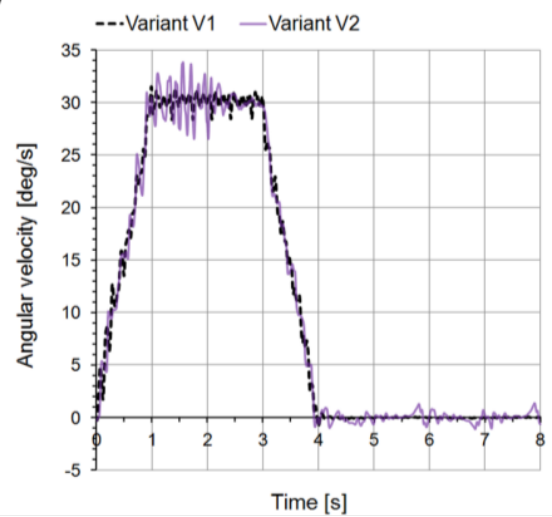

d)

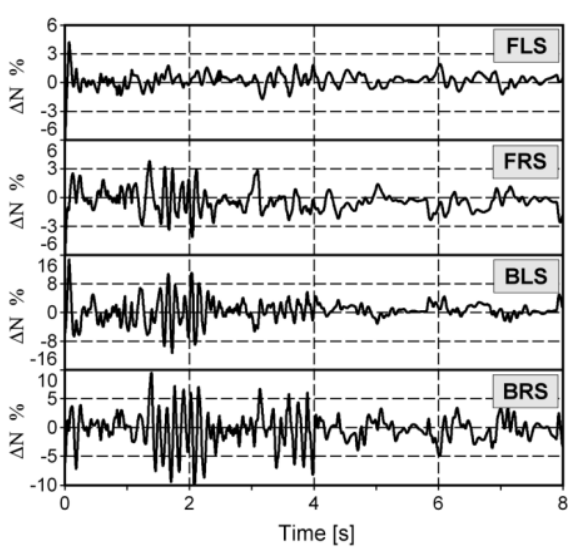

Fig. 5. Calculation results for configuration 1: a) a trajectory of the centre of mass of the load, b) the speed of rotation of the body relative to the chassis, c) a distribution of the support loads, d) a percentage comparison of the changes in variant $\mathrm{V} 2$ of support loads $(\Delta N)$ in relation to variant $\mathrm{V} 1$ (FLS - front left support, FRS - front right support, BLS - back left support, BRS - back right support)

a)

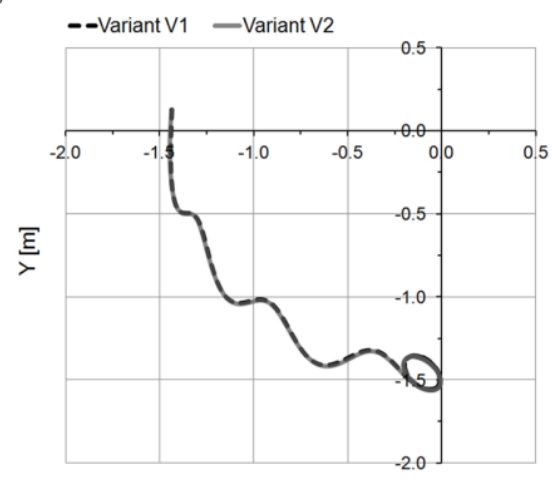

$\mathrm{Z}[\mathrm{m}]$

c)

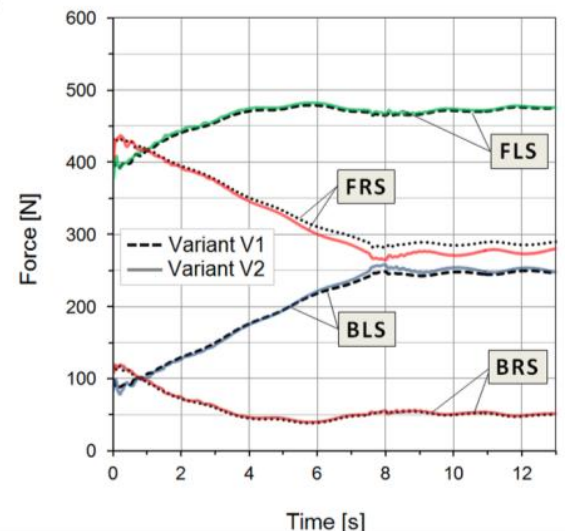

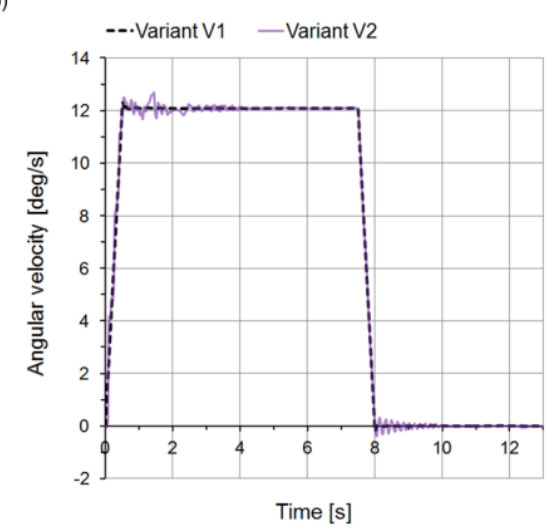

d)

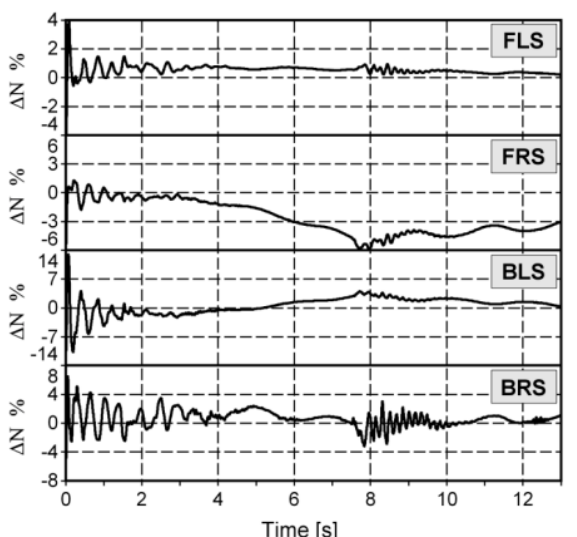

Fig. 6. Calculation results for configuration 2: a) a trajectory of the centre of mass of the load, b) the speed of rotation of the body relative to the chassis, c) a distribution of the support loads, $d$ ) a percentage comparison of the changes in variant $\mathrm{V} 2$ of support loads $(\Delta \mathrm{N})$ in relation to variant $\mathrm{V} 1$ (FLS - front left support, FRS - front right support, BLS - back left support, BRS - back right support) 


\section{SUMMARY AND CONCLUSIONS}

This paper presents the results of numerical analyses of the computational model of an experimental crane which were carried out in order to evaluate the impact of the support system's kinematic structure on selected kinematic and dynamic quantities of a crane. Two variants of the model were developed - one with supports with bilateral constraints (V1) and the other with supports with unilateral constraints (V2). The stiffnesses and dampings of the supports were determined experimentally. The model did not include flexibilities or clearances in the connections, except for the supports.

On the basis of the numerical analyses, it was found that:

- A support system with unilateral constraints introduces multiple distortions of time characteristics of the monitored kinematic and dynamic quantities. These distortions are caused by the possibility of the supports moving relative to the base (slides in the clearance area) and by impact loads which are caused by the interaction between mountings of force sensors (the upper one is connected to the support screw and the lower one to the base). The maximum excess of the support loads, which is due to the above-mentioned causes (Fig. 5d), does not exceed $14.7 \%$ of the value which was obtained for a system with supports with bilateral constraints.

- The time characteristics of selected kinematic and dynamic quantities which were obtained for variant $\mathrm{V} 1$ of the model, with the same input functions as those which were used for variant V2, are almost completely free from distortions. At subsequent moments of time, particular kinematic and dynamic quantities assume values which correspond to the average values that were determined for the model with unilateral constraints.

- Although a support system with supports having bilateral constraints is inconsistent with a crane's real support system, it can be used in experimental models. Both kinematic and dynamic quantities assume proper values for this variant of the model under the condition that the input functions that are used for the motion are chosen so that the structure does not lose its stability (so that no fictitious forces appear in the model).

- On the basis of the calculations it was found that an increase in the coefficient of friction between support screws and the base has a positive influence on the dynamic loads of the supports - distortions of time characteristics are less frequent and the load changes of the supports are smaller relative to the loads in the system with bilateral constraints.

\section{REFERENCES}

1. Araya H., Kakuzena M., Kinugawab H., Arai T. (2004), Level luffing control system for crawler cranes, Automation in Construction, 13 689-697.

2. Blackburn D., Lawrence J., Danielson J., Singhose W., Kamoi T., Taura A. (2010), Radial-motion assisted command shapers for nonlinear tower crane rotational slewing, Control Engineering Practice, 18, 523-531.

3. Cha J.H., Roh M.I., Lee K.Y. (2010), Dynamic response simulation of a heavy cargo suspended by a floating crane based on multibody system dynamics, Ocean Engineering, 37 (14-15), 1273-1291.
4. Geisler T., Sochacki W. (2011), Modelling and research into the vibrations of truck crane, Scientific Research of the Institute of Mathematics and Computer Science, 1 (10), 49-60.

5. Giergiel J. (1986), Damping of mechanical vibrations (in Polish), Wyd. AGH, Kraków.

6. Jerman B., Podrzaj P., Kramar J. (2004), An investigation of slewing-crane dynamics during slewing motion-development and verification of a mathematical model, International Journal of Mechanical Sciences, 46, 729-750.

7. Kilicaslan S., Balkan T., Ider S.K. (1999), Tipping loads of mobile cranes with flexible booms, Journal of Sound and Vibration, 223 (4), 645-657.

8. Kłosiński J. (2005), Swing-free stop control of the slewing motion of a mobile crane, Control Engineering Practice, 13, 451-460.

9. Kłosiński J., Trąbka A. (2010), Frequency analysis of vibratory device model (in Polish), Pneumatyka, 1, 46-49.

10. Maczyński A. (2000), The influence of crane support flexibility on load motion, 4th EUROMECH Solid Mechanics Conference, Book of abstracts II, General sessions, Metz, France, June 26-30, 519.

11. Mijailović R. (2011), Modelling the dynamic behaviour of the truckcrane, Transport, 26 (4), 410-417.

12. Paszkiewicz T., Osiński M., Wojciech S. (1999), Dynamic analysis of an offshore crane on offshore installations, 4th International Offshore Cranes Conference, Stavanger, Norway, April 26-28, 2-38.

13. Smoczek J. (2014), Fuzzy crane control with sensorless payload deflection feedback for vibration reduction, Mechanical Systems and Signal Processing, 46, 70-81.

14. Smoczek J., Szpytko J. (2012), Fuzzy rules-based approach to estimate the availability of transportation system, International Journal of Intelligent Systems Technologies and Applications, 11 (1/2), 117-137.

15. Smoczek J., Szpytko J. (2014), Evolutionary algorithm-based design of a fuzzy TBF predictive model and TSK fuzzy anti-sway crane control system, Engineering Applications of Artificial Intelligence, 28, 190-200.

16. Sochacki W. (2007), The dynamic stability of a laboratory model of a truck crane, Thin-Walled Structures, 45, 927-930.

17. Sosna E. (1984), Influence of flexibility of support system on dynamics of the telescopic mobile crane (in Polish), Praca doktorska, Politechnika Łódzka.

18. Terashima K., Shen Y., Yano K. (2007), Modeling and optimal control of a rotary crane using the straight transfer transformation method, Control Engineering Practice, 15, 1179-1192.

19. Trąbka A. (2014), Dynamics of telescopic cranes with flexible structural components, International Journal of Mechanical Sciences, $88,162-174$.

20. Trombski M. (Editor) (2003), Control algorithms of telescopic crane operating cycle (in Polish), Wyd. ATH w Bielsku-Białej.

21. Uchiyama N. (2009), Robust control of rotary crane by partial-state feedback with integrator, Mechatronics, 19, 1294-1302.

22. Uchiyama N., Ouyang H., Sano S. (2013), Simple rotary crane dynamics modeling and open-loop control for residual load sway suppression by only horizontal boom motion, Mechatronics, 23 , 1223-1236.

23. Wu J.J. (2006), Finite element analysis and vibration testing of a three-dimensional crane structure, Measurement, 39, 740-749. 